\title{
Optimized decellularization protocol including $\alpha$-Gal epitope reduction for fabrication of an acellular porcine annulus fibrosus scaffold
}

\author{
Lien-Chen Wu - Yi-Jie Kuo $\cdot$ Fu-Wen Sun • Chia-Hsien Chen • Chang-Jung Chiang • \\ Pei-Wei Weng $\cdot$ Yang-Hwei Tsuang $\cdot$ Yi-You Huang
}

Received: 21 September 2016/Accepted: 11 March 2017/Published online: 24 March 2017

(C) The Author(s) 2017. This article is an open access publication

\begin{abstract}
Recent advances in tissue engineering have led to potential new strategies, especially decellularization protocols from natural tissues, for the repair, replacement, and regeneration of intervertebral discs. This study aimed to validate our previously reported method for the decellularization of annulus fibrosus (AF) tissue and to quantify potentially antigenic $\alpha$-Gal epitopes in the decellularized tissue. Porcine AF tissue was decellularized using different freeze-thaw temperatures, chemical detergents, and
\end{abstract}

L.-C. Wu · F.-W. Sun · Y.-Y. Huang $(\bowtie)$

Institute of Biomedical Engineering, College of

Engineering, College of Medicine, National Taiwan

University, No. 1, Sec. 1, Jen-Ai Road, Taipei, Taiwan

e-mail: yyhuang@ntu.edu.tw

L.-C. $\mathrm{Wu} \cdot$ C.-H. Chen - C.-J. Chiang ·

P.-W. Weng · Y.-H. Tsuang

Department of Orthopedics, Shuang Ho Hospital, Taipei

Medical University, Taipei 23561, Taiwan

Y.-J. Kuo

Department of Orthopedics, Taipei Medical University

Hospital, Taipei 110, Taiwan

L.-C. Wu · Y.-J. Kuo · C.-J. Chiang ·

P.-W. Weng · Y.-H. Tsuang

Department of Orthopaedics, School of Medicine, College of Medicine, Taipei Medical University, Taipei 11031,

Taiwan incubation times in order to determine the optimal method for cell removal. The integrity of the decellularized material was determined using biochemical and mechanical tests. The $\alpha$-Gal epitope was quantified before and after decellularization. Decellularization with freeze-thaw in liquid nitrogen, an ionic detergent $(0.1 \%$ SDS), and a $24 \mathrm{~h}$ incubation period yielded the greatest retention of GAG and collagen relative to DNA reduction when tested as single variables. Combined, these optimal decellularization conditions preserved more GAG while removing the same amount of DNA as the conditions used in our previous study. Components and biomechanical properties of the AF matrix were retained. The decellularized AF scaffold exhibited suitable immunecompatibility, as evidenced by successful in vivo remodeling and a decrease in the $\alpha$-Gal epitope. Our study defined the optimal conditions for decellularization of porcine AF tissues while preserving the biological composition and mechanical properties of the scaffold. Under these conditions, immunocompatibility was evidenced by successful in vivo remodeling and reduction of the $\alpha$-Gal epitope in the decellularized material. Decellularized AF scaffolds are potential candidates for clinical applications in spinal surgery.

Keywords $\alpha$-Gal epitope - Annulus fibrosus . Intervertebral disc $\cdot$ Decellularization · Tissue engineering 


\section{Introduction}

Intervertebral disc herniation is a common cause of severe lower back pain and disability. The available surgical treatments, including discectomy and spinal fusion, are primarily palliative and are meant to eliminate pain in the short term. They neither repair the disc nor restore the normal biological and mechanical properties of the spine. Such procedures can limit mobility and may even further alter the biomechanics of the spine, leading to further degeneration of adjacent segments. Thus, new strategies for treating damaged intervertebral discs are needed. Recent advances in tissue engineering present potential new strategies to repair, replace, or regenerate degenerative discs (Mercuri et al. 2011; Schek et al. 2011; Yang et al. 2009).

The intervertebral disc (IVD) provides a cushion between the vertebrae, protecting them from compression and other stress. Each disc comprises a soft center (the nucleus pulposus) surrounded by a tough outer wall of collagen and proteoglycans (the annulus fibrosus). Tears and fissures of the annulus fibrosis (AF) due to decreased integrity of the extracellular matrix or traumatic injury result in protrusion of the nucleus pulposus (NP). The low vascularity and low cellularity of the AF limit its intrinsic healing capacity, as with articular cartilage (Bron et al. 2009; Mwale et al. 2011). Treatments to repair such herniation without discectomy require $\mathrm{AF}$ repair that is suitable to withstand the intradiscal pressure (Guterl et al. 2013). Direct suture of the AF is technically very demanding due to limited space and potential injury to the proximal neurological structures (Guterl et al. 2013). Implants for closing the damaged AF are commercially available, but these do not prevent AF degeneration or maintain the biological AF structure in ensuing years (Bron et al. 2009; Chan and GantenbeinRitter 2012). Materials that approximate the extracellular matrix (ECM) of the AF, a key contributor to its high strength, are thus highly attractive for such repair.

One tissue engineering strategy for developing biomaterials is to decellularize xenogeneic tissues by removing immunogenic cells. This method has been successfully used to develop biomaterials for use in cartilage, the meniscus, ligaments, and tendons, with impressive results (Gilbert et al. 2006, 2009; Stone et al. 2007; Wu et al. 2014; Xu et al. 2014). Xenogeneic and allogeneic cellular antigens are recognized as foreign by the host, thereby inducing an inflammatory response or an immune-mediated rejection of the tissue. However, ECM components such as collagens, laminins, and polysaccharides, are highly conserved among species and are tolerated well even by xenogeneic recipients (Gilbert et al. 2006), (Gilbert 2012). The goal of a decellularization protocol is to remove all cellular and nuclear materials to prevent immune and inflammatory reactions while minimizing any adverse effect on the composition, biological activity, and mechanical integrity of the remaining ECM. When properly processed to remove cellular antigens that can induce immune rejection without damaging the ECM, ECM scaffolds can serve as potent sources of cues that promote constructive remodeling of tissue after injury or degeneration.

We previously reported a preliminary method for decellularizing porcine $\mathrm{AF}$ to yield a biological scaffold for use in human AF defect substitution (Wu et al. 2014). Our method produced a scaffold with low DNA content that retained most of the original biological composition and properties, with some loss of glycosaminoglycan (GAG). The present study aimed to manipulate several protocol variables in this method to determine conditions that would maximize retention of the scaffold components collagen and GAG while minimizing the DNA content. A secondary objective was to determine the biochemical and biomechanical properties of the acellular AF scaffold and to preliminarily evaluate its biocompatibility using $\alpha$-Gal epitope quantification, in vitro cytotoxicity assays, and an in vivo immuno-compatibility study.

\section{Materials and methods}

Tissue harvest

This study used xenogeneic tissue to facilitate tissue sourcing. Fresh porcine lumbar spines were obtained en bloc from a local abattoir (Taoyuan County, Taiwan) within $2 \mathrm{~h}$ post-mortem. The AF tissue was harvested from the IVD by gently excising and washing in phosphate-buffered saline (PBS) to remove excess blood. To preclude contamination by the surrounding tissue and NP, the outermost and innermost layers of the AF were carefully removed. Samples were then placed in neutral buffered formalin 
for histologic analysis or frozen and stored in PBSmoistened filter paper at $-20{ }^{\circ} \mathrm{C}$.

Comparison of decellularization methods

by biochemical assays

\section{Protocol 1: Freeze-thaw in $-80^{\circ} \mathrm{C}$ versus liquid nitrogen $\left(-196^{\circ} \mathrm{C}\right)$}

This decellularization method was a modification of the method of Booth et al. (2002), Stapleton et al. (2008). Briefly, the AF samples were randomly divided into two groups $(n=6)$ and decellularized by exposing the tissue to freeze-thaw. Porcine AF was either frozen at $-80{ }^{\circ} \mathrm{C}$ for $22 \mathrm{~h}$ (Group A), or in liquid nitrogen $\left(-196{ }^{\circ} \mathrm{C}\right)$ for $22 \mathrm{~h}$ (Group B), and then thawed in an incubator at $37{ }^{\circ} \mathrm{C}$ for $2 \mathrm{~h}$. Samples were then incubated with agitation in hypotonic buffer (10 $\mathrm{mM}$ tris- $\mathrm{HCl}, \mathrm{pH} 8.0$ ) with $0.1 \%$ EDTA and protease inhibitors (aprotinin $10 \mathrm{KIU} / \mathrm{mL}$; Sigma, USA) at $37{ }^{\circ} \mathrm{C}$ for $24 \mathrm{~h}$, then in $0.1 \%$ sodium dodecyl sulfate (SDS, Wako, Japan) at $45^{\circ} \mathrm{C}$ for 24 .

After washing, the samples were incubated in deoxyribonclease (DNase 50U/mL; Sigma, USA) and ribonuclease (RNase 1U/mL; Sigma, USA) in Tris buffer ( $50 \mathrm{mM}$ tris- $\mathrm{HCl}, 10 \mathrm{mM}$ magnesium chloride, and $50 \mathrm{mg} / \mathrm{mL}$ bovine serum albumin at $\mathrm{pH}$ 7.5) for $3 \mathrm{~h}$ at $37^{\circ} \mathrm{C}$ with gentle agitation. The tissues were then washed three times in PBS at $37{ }^{\circ} \mathrm{C}$ for $8 \mathrm{~h}$. Fresh porcine AF samples (controls) were stored at $-20{ }^{\circ} \mathrm{C}$. All AF samples were then evaluated by biochemical assay (sulfated glycosaminoglycan assay, hydroxyproline assay, and DNA assay, detailed methods are described later) to compare AF properties between tissues treated with and without decellularization.

\section{Protocol 2: $0.1 \%$ SDS versus $1 \%$ Triton $x-100$}

Freeze-thaw in liquid nitrogen was used, as it resulted in more effective decellularization than did freezethaw at $-80{ }^{\circ} \mathrm{C}$. The AF samples were randomly divided into $\mathrm{C}$ and $\mathrm{D}$ groups $(\mathrm{n}=6)$, and all samples were freeze-thawed in liquid nitrogen and then incubated in a hypotonic buffer at $37{ }^{\circ} \mathrm{C}$ for $24 \mathrm{~h}$. The group $\mathrm{C}$ samples were then decellularized in tris$\mathrm{HCl}$ buffer containing $0.1 \%$ SDS, $0.1 \%$ EDTA, and 10 $\mathrm{KIU} / \mathrm{mL}$ aprotinin at $4{ }^{\circ} \mathrm{C}$ for $24 \mathrm{~h}$. The group D samples were decellularized in tris- $\mathrm{HCl}$ buffer with $1 \%$ Triton X-100 (Sigma, USA), 0.1\% EDTA and 10
$\mathrm{KIU} / \mathrm{ml}$ aprotinin at $4{ }^{\circ} \mathrm{C}$ for $24 \mathrm{~h}$. The samples were washed and incubated with DNase and RNase in Tris buffer, washed for $8 \mathrm{~h}$ in PBS, and evaluated by biochemical assay as described in Protocol 1.

\section{Protocol 3: Comparison between decellularization times of 24 versus 48 vs. 72 h using $0.1 \%$ SDS}

Freeze-thaw in liquid nitrogen followed by treatment with $0.1 \%$ SDS showed better decellularization results compared to $1 \%$ Triton $\mathrm{X}-100$, and was therefore selected as the optimal method. AF samples were randomly divided into 3 groups $(n=6 /$ group $)$, freeze-thawed in liquid nitrogen and then incubated in a hypotonic buffer at $37{ }^{\circ} \mathrm{C}$ for $24 \mathrm{~h}$. The samples were then decellularized in tris- $\mathrm{HCl}$ buffer containing $0.1 \%$ SDS, $0.1 \%$ EDTA and $10 \mathrm{KIU} / \mathrm{mL}$ aprotinin at $4{ }^{\circ} \mathrm{C}$ for $24 \mathrm{~h}$ (group E), $48 \mathrm{~h}$ (group F), or $72 \mathrm{~h}$ (group $\mathrm{G})$. The samples were washed, incubated with DNase and RNase in Tris buffer, washed for $8 \mathrm{~h}$ in PBS and evaluated by biochemical assay as described in Protocol 1.

Optimal decellularization method

Based on our optimization data, we treated AF samples $(n=10)$ by freeze-thaw in liquid nitrogen, incubation in a hypotonic buffer at $37^{\circ} \mathrm{C}$ for $24 \mathrm{~h}$, and decellularization in $0.1 \%$ SDS, $0.1 \%$ EDTA and 10 $\mathrm{KIU} / \mathrm{mL}$ aprotinin at $4{ }^{\circ} \mathrm{C}$ for $24 \mathrm{~h}$. After washing, samples treated with DNase and RNase, stored, and assayed as described in the previous section.

Biochemical assays

\section{Sulfated glycosaminoglycan assay}

The proteoglycan content of the tissue was determined by measuring the amount of sulfated glycosaminoglycans in the papain-digested tissue using the 1,9dimethylmethylene blue (DMMB) dye binding assay and spectrophotometry (Farndale et al. 1986). The AF tissue specimens $(n=6)$ were first lyophilized (dry weight, $50 \mathrm{mg}$ ) and then digested in papain buffer $(250 \mu \mathrm{L}$ papain in $\mathrm{PBS}$ at $\mathrm{pH} 6.0$ with $150 \mathrm{mM}$ sodium chloride, $55 \mathrm{nM}$ sodium citrate, $5 \mathrm{mM}$ cysteine- $\mathrm{HCl}$, and $5 \mathrm{mM} \mathrm{Na} \mathrm{F}_{2}$ EDTA) at $60{ }^{\circ} \mathrm{C}$ for $12 \mathrm{~h}$. The supernatant fluid was measured at $530 \mathrm{~nm}$ using chondroitin sulfate as a standard. 


\section{Hydroxyproline assay}

The collagen content was quantified using a commercially available assay kit (hydroxyproline assay kit, BioVision, Milpitas, CA, USA) (Zhang et al. 2012). The AF specimens $(n=6)$ were first lyophilized and then hydrolyzed in $6 \mathrm{M} \mathrm{HCl}$ at $120{ }^{\circ} \mathrm{C}$ for $3 \mathrm{~h}$ and neutralized using $\mathrm{NaOH}$. The hydroxyproline content was determined using the chloramine-T/Ehrlich's reagent assay and spectrophotometry at $550 \mathrm{~nm}$. The concentration of hydroxyproline was then calculated by interpolation from a hydroxyproline standard curve.

\section{DNA assay}

The residual cells were determined by DNA assay using the ReliaPrep gDNA Tissue Miniprep System (Promega, Fitchburg, WI, USA) (Rabelo-Goncalves et al. 2014). The DNA was extracted from both native and decellularized AF. Six AF specimens (wet weight, $25 \mathrm{mg}$ ) were used. The DNA was extracted using a DNA isolation kit and then quantified according to standard protocols by measuring the absorbance at 260/280 nm using a spectrophotometer (NanoDrop ND 1000; Thermo Scientific, Waltham, MA, USA).

\section{Histology}

Tissue specimens $(\mathrm{n}=5)$ were fixed in neutral buffered formalin for $48 \mathrm{~h}$, then embedded in paraffin wax and sectioned at $6 \mu \mathrm{m}$ thickness using a microtome. Samples were characterized histologically by hematoxylin and eosin staining (H\&E, Bios Europe, Skelmersdale, UK) to evaluate cellular content and the AF structure and by Masson's Trichrome Staining (MT staining) to visualize collagen distribution and orientation. Glycosaminoglycans (GAGs) were visualized by periodic acid-schiff (PAS) staining.

\section{Scanning electron microscopy (SEM)}

Fresh-frozen AF and the decellularized AF scaffolds prepared by optimal decellularization method (OC) were harvested and fixed in $4 \%$ paraformaldehyde (wt/vol) for 2 days. The samples $(n=5)$ underwent sequential dehydration and were sputter-coated with gold (5 nm thick) to impart electrical conductivity.
The specimens were then evaluated and imaged using SEM (JSM 5600, JEOL, Tokyo, Japan) to evaluate the ultra-structure of the AF surfaces.

\section{Compression (indentation) test}

Compression tests were conducted using a Universal Testing Machine. Uni-axial compression tests were performed at room temperature $\left(26^{\circ} \mathrm{C}\right)$ and $60 \%$ relative humidity. The constant deformation rate was set at $0.1 \mathrm{~mm} / \mathrm{sec}$ for all materials examined $(\mathrm{n}=6)$. Force and deformation (changes in length) were recorded electronically, and the resulting stress-strain compression curves were constructed.

$\alpha$-Gal ELISA test sample processing

Native AF and decellularized AF scaffolds (OC) were thoroughly rinsed in ice-cold PBS $(0.02 \mathrm{M}, \mathrm{pH}$ 7.0-7.2) for a brief washing and weighing before homogenization. The tissues were minced into small pieces and homogenized in a PBS using a glass homogenizer on ice. The resulting suspension was subjected to ultrasonication to further break down cell membranes and then centrifuged for $15 \mathrm{~min}$ at $1500 \times g$. The supernatant was then removed and assayed as follows.

Quantification of $\alpha$-Gal content

The ELISA test for $\alpha$-Gal was carried out as previously reported (Naso et al. 2011, 2013) using a commercially available assay kit (Alpha-Galactosyl ELISA Kit, BlueGene Biotech, Shanghai, China). Microtitre-plate wells pre-coated with antibody were loaded with $100 \mu \mathrm{L}$ of supernatant derived from native AF tissue $(\mathrm{n}=8)$ and decellularized AF tissue $(\mathrm{n}=8)$. Conjugate $(50 \mu \mathrm{L})$ was then added to each well, and the mixture was incubated for $1 \mathrm{~h}$ at $37{ }^{\circ} \mathrm{C}$ in darkness. The micro-titer plate was washed 5 times; after the final wash, the plate was inverted and blotted dry.

After drying, $100 \mu \mathrm{L}$ of horseradish peroxidase substrate buffer was added to each well and incubated for $15 \mathrm{~min}$ at room temperature in darkness. Stop solution $(50 \mu \mathrm{L})$ was then added to each well, and the Optical Density (OD) was immediately read at $450 \mathrm{~nm}$ using a micro-titer plate reader. 
Cytotoxicity of decellularized AF in a trans-well insert model

Samples of decellularized AF scaffolds (OC) were prepared and placed at the bottom of trans-well insert wells before cytotoxicity testing. The trans-wells used in this study were $24 \mathrm{~mm}$ in diameter, with a membrane pore size of $0.4 \mu \mathrm{m}$ (Costar, Transwell, Corning, NY, USA). The trans-wells were placed onto 24-well culture plates, seeded with NIH3T3 fibroblasts $\left(3 \times 10^{3}\right.$ cells/well), and incubated for 1 or 2 days. For each sample, 5 wells were prepared.

For controls, the cells were cultured in 24-well plates with trans-well inserts but without AF tissue. After co-culture, the insert wells were removed. Viability of the target NIH3T3 fibroblasts was measured using 3-(4,5-dimethylthiazol-2-yl)-5-(3-carboxymethoxyphenyl)-2-(4-sulfophenyl)-2H-tetrazolium (MTS, Promega) according to the manufacturer's instructions.

In vivo immuno-compatibility study

The host response to decellularized $\mathrm{AF}$ was assessed in 6 male Wistar rats (300-350 g), and all experiments were conducted according to the principles and procedures described by the Institutional Animal Care and Use Committee of National Taiwan University. Briefly, two non-contiguous coccygeal intervertebral discs were selected for the study. After anesthesia, a longitudinal incision was created over the tail region, and the posterior surface of the coccygeal intervertebral discs was exposed by anatomic dissection along the skin incision. Care was taken not to interrupt the outer annular fibers of the disc. A $1 \times 1 \mathrm{~mm}$ rectangular excision was made through the annulus fibrosus and into the nucleus pulposus.

The two non-contiguous discs were delegated to the control group (box incision only) and the repair group, in which the box defect was implanted with decellularized AF scaffold (sterilized) and sutured using 6-0 non-absorbable polypropylene. In each group, rats were further divided into 2 subgroups, with 2 healing times, 7 and 14 days. The intervertebral disc levels of the annular incisions were randomized from animal to animal to diminish any level-specific differences. Upon euthanization, the discs were harvested and examined histologically for signs of inflammatory response (H\&E staining) and ECM production (MT and PAS staining).

Statistical analysis

All data are presented as the mean \pm standard deviation (SD). Analysis of variance (ANOVA) was implemented to test differences between 3 or 4 groups, and independent $t$-tests were carried out to compare 2 groups. All statistics were two-sided, and $p<0.05$ was considered statistically significant. Statistical analyses were performed using SPSS statistical software for Windows (version 22.0, IMB Corp., Armonk, NY).

\section{Results}

Comparison of decellularization methods by biochemical assays

The quantities of decellularized AF components under various freeze-thaw temperatures, detergents, and times are summarized in Table 1. The levels of ECM components were lower after decellularization in liquid nitrogen $\left(-196{ }^{\circ} \mathrm{C}\right)$ than in control $\mathrm{AF}$ samples. However, samples decellularized with liquid nitrogen had a higher content of GAG, collagen and DNA compared to those decellularized at $-80{ }^{\circ} \mathrm{C}$.

More GAG and collagen content was preserved by decellularization in $0.1 \%$ SDS than in Triton X-100. However, the DNA content in the $0.1 \%$ SDS group was lower than in the Triton X-100 group and was therefore superior to Triton $\mathrm{X}-100$ for $\mathrm{AF}$ decellularization.

The DNA content was significantly lower after $24 \mathrm{~h}$ of decellularization and effectively removed after $72 \mathrm{~h}$. However, extension of the decellularization time resulted in greater losses of GAG and collagen. Thus, the ideal decellularization time was determined to be $24 \mathrm{~h}$.

The optimal decellularization conditions therefore included liquid nitrogen, $0.1 \%$ SDS and a decellularization period of $24 \mathrm{~h}$. There were no differences in GAG and collagen content between AF treated with the optimal decellularized method and the native AF group, while the DNA content of the decellularized samples was $85.7 \%$ lower than that of the control samples (calculated as [9.1 - 63.55]/63.55). 
Table 1 Results of biochemical assays of AF in decellularization

\begin{tabular}{|c|c|c|c|}
\hline & $\begin{array}{l}\text { GAG content } \\
(\mu \mathrm{g} / \mathrm{mg})\end{array}$ & $\begin{array}{l}\text { Collagen content } \\
(\mu \mathrm{g} / \mathrm{mg})\end{array}$ & $\begin{array}{l}\text { DNA content } \\
(\mathrm{ng} / \mathrm{mg})\end{array}$ \\
\hline \multicolumn{4}{|l|}{ Freeze-thaw temperatures } \\
\hline Fresh $\mathrm{AF}(\mathrm{n}=6)$ & $107.07 \pm 7.24$ & $102.15 \pm 9.93$ & $46.31 \pm 5.92$ \\
\hline Freeze-thaw in $-80{ }^{\circ} \mathrm{C}(\mathrm{n}=6)$ & $94.03 \pm 7.18^{\mathrm{a}}$ & $93.62 \pm 5.26^{\mathrm{a}}$ & $10.38 \pm 1.19^{\mathrm{a}}$ \\
\hline Freeze-thaw in $-196{ }^{\circ} \mathrm{C}$ liquid nitrogen refrigeration $(n=6)$ & $99.57 \pm 7.70^{\mathrm{a}, \mathrm{b}}$ & $101.75 \pm 6.97^{\mathrm{a}, \mathrm{b}}$ & $12.03 \pm 2.52^{\mathrm{a}, \mathrm{b}}$ \\
\hline \multicolumn{4}{|l|}{ Detergents } \\
\hline Fresh AF $(n=6)$ & $150.97 \pm 4.60$ & $117.68 \pm 7.40$ & $73.22 \pm 5.43$ \\
\hline Decellularized in SDS $(n=6)$ & $142.85 \pm 4.9^{\mathrm{a}}$ & $108.58 \pm 11.58^{\mathrm{a}}$ & $12.34 \pm 3.14^{\mathrm{a}}$ \\
\hline Decellularized in Triton X-100 $(n=6)$ & $127.08 \pm 8.45^{\mathrm{a}, \mathrm{c}}$ & $100.79 \pm 10.86^{\mathrm{a}, \mathrm{c}}$ & $25.59 \pm 7.04^{\mathrm{a}, \mathrm{c}}$ \\
\hline \multicolumn{4}{|l|}{ Decellularization time } \\
\hline Fresh AF $(n=6)$ & $96.09 \pm 2.88$ & $120.94 \pm 4.33$ & $46.31 \pm 5.92$ \\
\hline Decellularization for $24 \mathrm{~h}(\mathrm{n}=6)$ & $82.77 \pm 6.17^{\mathrm{a}}$ & $109.72 \pm 2.96^{\mathrm{a}}$ & $11.07 \pm 2.17^{\mathrm{a}}$ \\
\hline Decellularization for $48 \mathrm{~h}(\mathrm{n}=6)$ & $47.49 \pm 6.25^{\mathrm{a}, \mathrm{d}}$ & $94.18 \pm 3.28^{\mathrm{a}, \mathrm{d}}$ & $9.16 \pm 2.11^{\mathrm{a}}$ \\
\hline Decellularization for $72 \mathrm{~h}(\mathrm{n}=6)$ & $14.44 \pm 2.90^{\mathrm{a}, \mathrm{d}, \mathrm{e}}$ & $89.80 \pm 5.85^{\mathrm{a}, \mathrm{d}, \mathrm{e}}$ & $4.23 \pm 1.34^{\mathrm{a}}$ \\
\hline \multicolumn{4}{|l|}{ Optimal decellularization methods (ODM) } \\
\hline Fresh AF $(n=10)$ & $121.63 \pm 5.66$ & $153.63 \pm 17.14$ & $63.55 \pm 3.71$ \\
\hline Optimal decellularization methods $(\mathrm{n}=10)$ & $114.77 \pm 10.61$ & $151.73 \pm 12.62$ & $9.10 \pm 2.20^{\mathrm{a}}$ \\
\hline
\end{tabular}

Data are presented as mean \pm standard deviation, and tested by analysis of variance for comparisons among 3 or 4 groups, or by independent $t$ test for comparison between 2 groups

$A F$ annulus fibrosus, $G A G$ glycosaminoglycans, $S D S$ sodium dodecyl sulfate

a Significantly different from Fresh AF group, $p<0.05$

b Significantly different from $-80{ }^{\circ} \mathrm{C}$ group, $p<0.05$

c Significantly different from SDS group, $p<0.05$

d Significantly different from 24 h group, $p<0.05$

e Significantly different from 48 h group, $p<0.05$
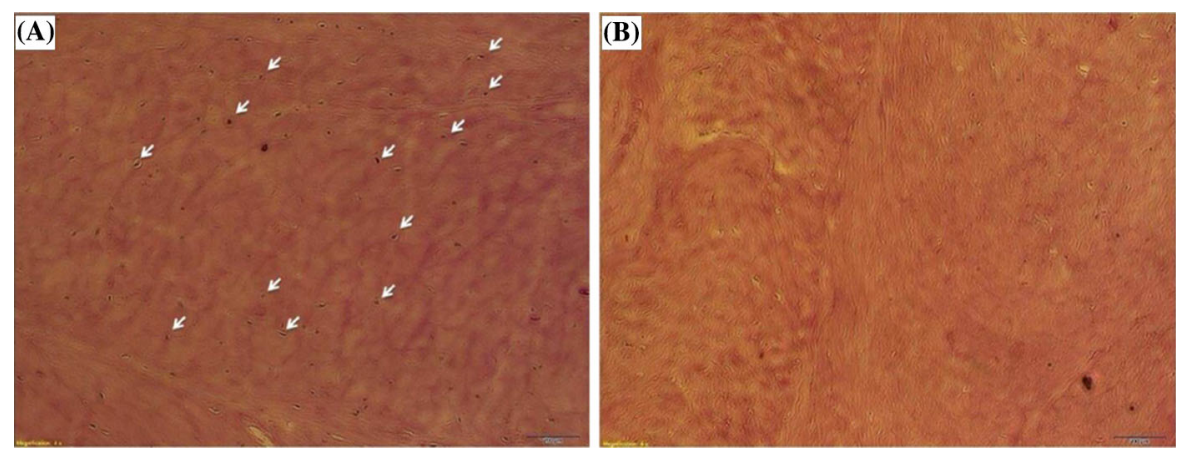

Fig. 1 Histology of annulus fibrosus (AF) with H\&E stain. Cellular material is a clearly embedded in the matrix and $\mathbf{b}$ rare-to-absent in decellularized AF. Both $\times 40$ magnification

Histologic analysis

On H\&E staining, native AF samples showed many cells to be embedded in the matrix (Fig. 1a). In tissues subject to decellularization under optimal conditions
(OC), cellular material was rare on $\mathrm{H} \& \mathrm{E}$ staining (Fig. 1b). On the other hand, MT staining revealed abundant collagen fibrils visible in both native and decellularized AF (OC) without obvious changes in morphology or distribution (Fig. 2). Many cells were 
seen scattered among collagen fibers in native $\mathrm{AF}$ samples (Fig. 2a).

PAS staining showed that both native AF and decellularized AF (OC) were rich in proteoglycans. Scaffolds prepared by different protocols showed differences in biochemical assays, although histologic assay showed no significant differences, suggesting that the decellularization process did not destroy the microstructure (Fig. 3).

\section{Scanning electron microscopy (SEM) analysis}

Scanning electron microscopy (SEM) revealed small pore-like structures on the surface of both native and decellularized AF surfaces (OC), confirming the retention of pore-like structures after decellularization (Fig. 4).

\section{Biomechanical testing}

Using force and deformation results, stress-strain compression curves were constructed and Young's modulus was obtained (Fig. 5). Compression testing showed no difference between native and decellularized AF scaffolds ( $p>0.05$, Student's $t$ test).

\section{Cytotoxicity assay}

In vitro toxicity studies of control and decellularized AF were conducted using the MTS assay with NIH3T3 cells. At all time points, OD values did not differ between the 2 groups $(p>0.05)$, indicating that the decellularized AF was not cytotoxic (Fig. 6).

In vivo immuno-compatibility study

After 7 days of healing, the annulus defect in all samples of both the control and repair groups was covered by scar tissue and populated mostly by mononuclear cells (Fig. 7). MT and PAS staining revealed that the densities of collagen and GAG were higher in the repair group than in controls. There was increased organization of collagen distribution in the repair group compared to the control group.
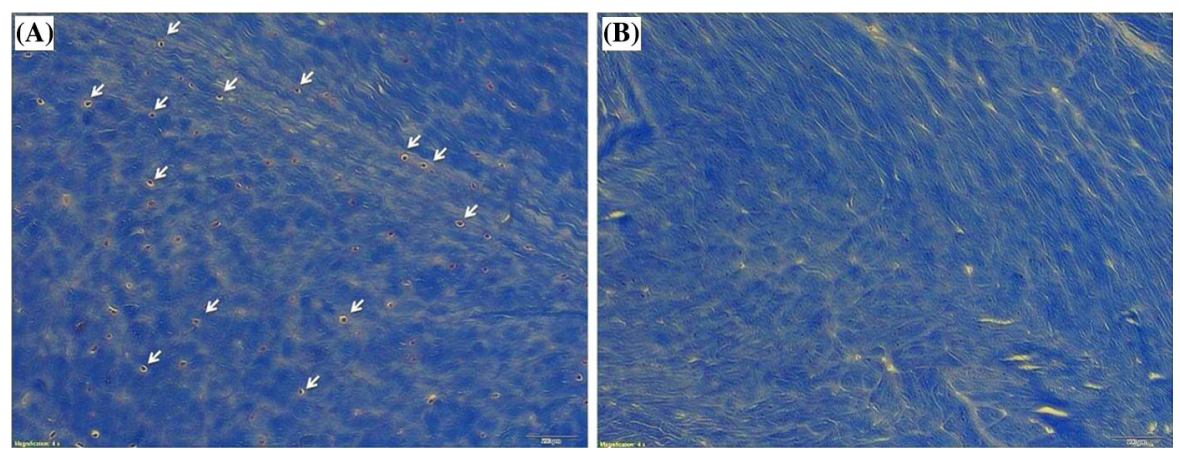

Fig. 2 a Fresh and b decellularized annulus fibrosus stained with Masson's Trichrome (MT) staining. $\times 40$ magnification
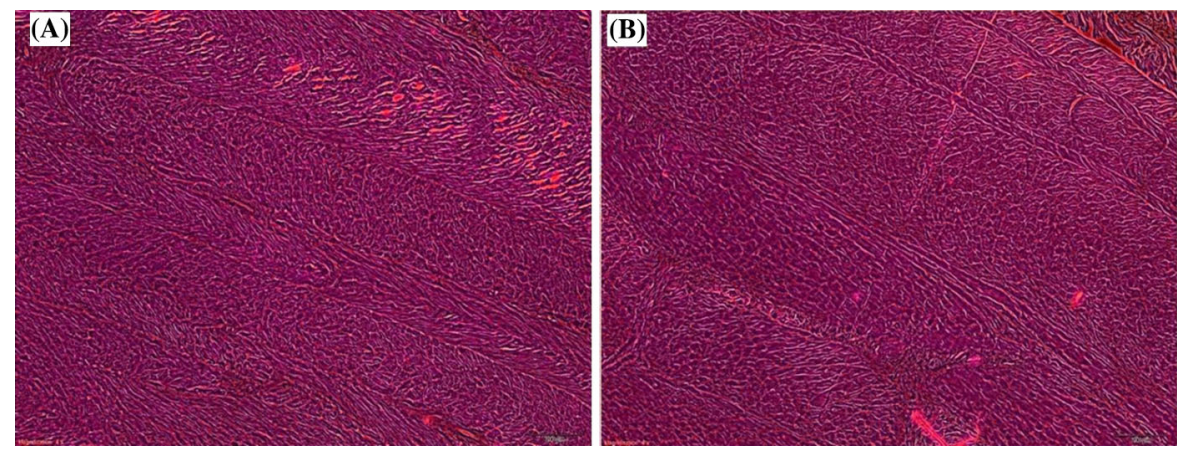

Fig. 3 a Fresh and $\mathbf{b}$ decellularized annulus fibrosus stained with Periodic acid-schiff (PAS) staining. $\times 40$ magnification 

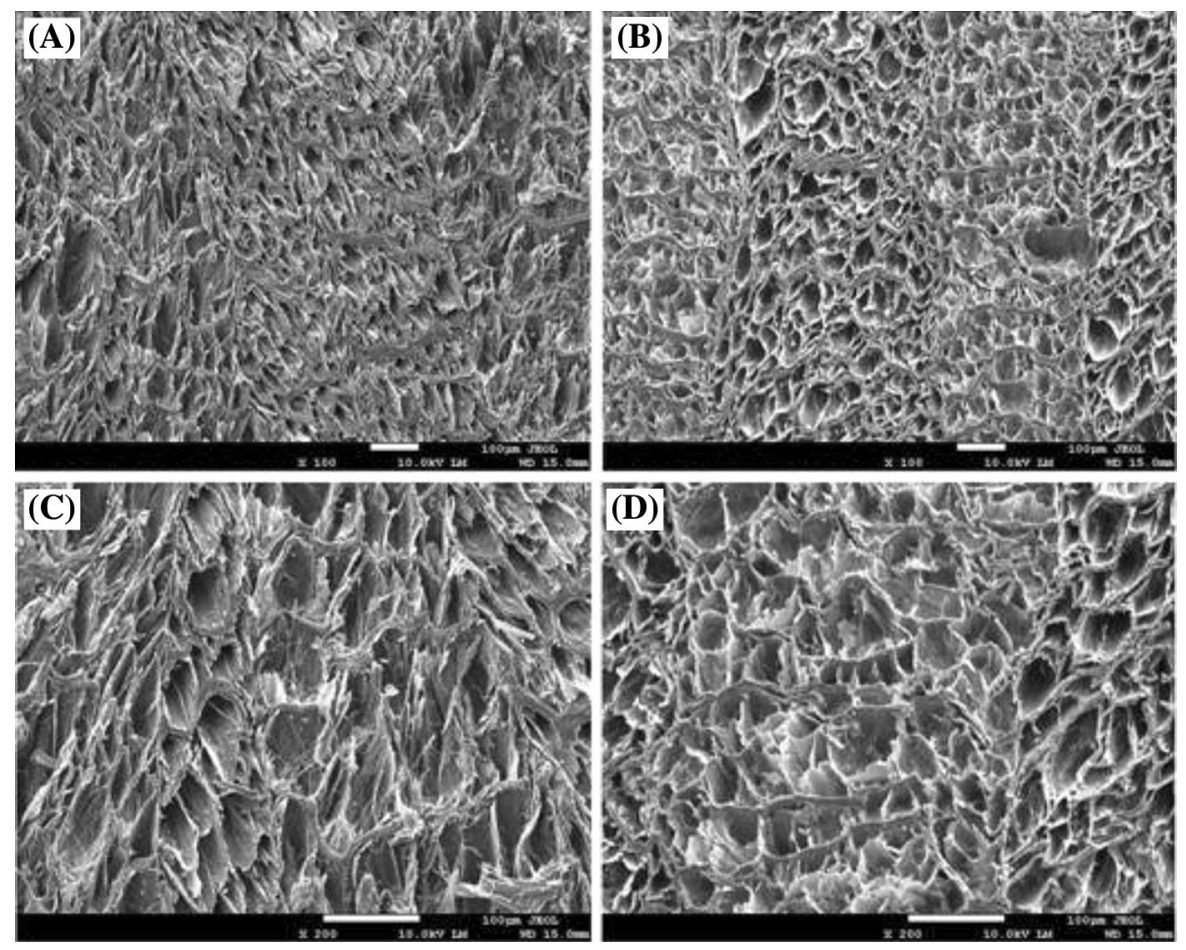

Fig. 4 Scanning electron microscopy (SEM) images of annulus fibrosus (AF). a Fresh AF has pore-like structures, $\times 100$ magnification. b Decellularized AF has confirmed retention of

After 14 days of healing, a decrease in mononuclear cells was noted in all samples (Fig. 8). MT and PAS staining revealed that the density of collagen and GAG was still higher in the repair group than in the control group. The density of collagen and GAG was also higher after 14 days of healing than after 7 days. Tissue remodeling was evident at multiple sites, and mononuclear and fibroblast-like cells were found deep within the matrix in both groups.

Quantification of $\alpha$-Gal content

The $\alpha$-Gal content was significantly lower in decellularized than in control AF $(p<0.001)$. Treatment of AF tissues under optimal decellularization conditions resulted in apparent removal of the $\alpha$-Gal xenoantigen (Fig. 9).

\section{Discussion}

This study investigated optimization of decellularization conditions on AF tissue to identify conditions that

pore-like structures on the AF surface, $\times 100$ magnification. c Fresh AF, $\times 200$ magnification. d Decellularized AF, $\times 200$ magnification

maximize retention of ECM properties in the resulting AF scaffold while minimizing toxicity and immunogenic factors such as DNA. Our data suggested that samples decellularized in liquid nitrogen had higher GAG, collagen, and DNA content compared to those decellularized at $-80{ }^{\circ} \mathrm{C}$. More GAG and collagen were preserved by decellularization in $0.1 \%$ SDS than in Triton X-100, with lower DNA content remaining. A decellularization time of $24 \mathrm{~h}$ maximized GAG and collagen preservation while decreasing DNA content relative to that of controls. Results of $\alpha$-Gal epitope quantitation, in vitro cytotoxicity assays, and an in vivo immuno-compatibility study all showed that decellularization with liquid nitrogen in the presence of $0.1 \%$ SDS for $24 \mathrm{~h}$ greatly reduced the immunogenicity of porcine AF.

A number of studies have investigated decellularization protocols using different chemical, physical, and enzymatic methods (Dahl et al. 2003; Hongo et al. 2008; Huang et al. 2011; Rieder et al. 2004; Woods and Gratzer 2005). Since any processing steps intended to remove cells could alter the native threedimensional architecture of the ECM, the goal of most 

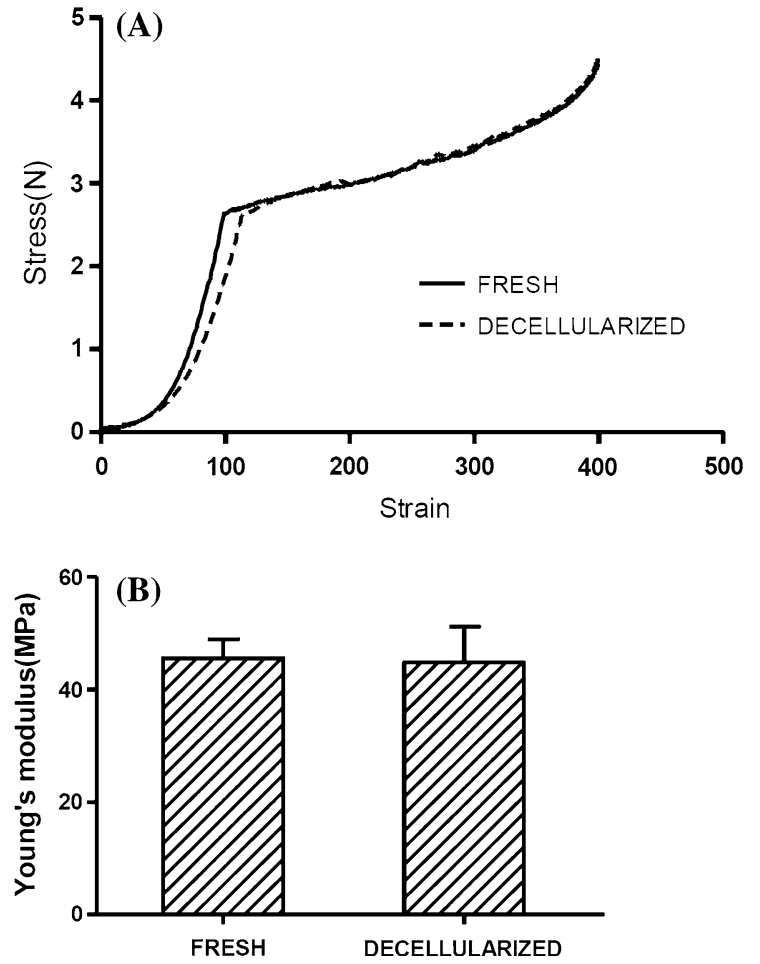

Fig. 5 Biomechanical testing of annulus fibrosus. a Stressstrain compression curves. b Young's modulus

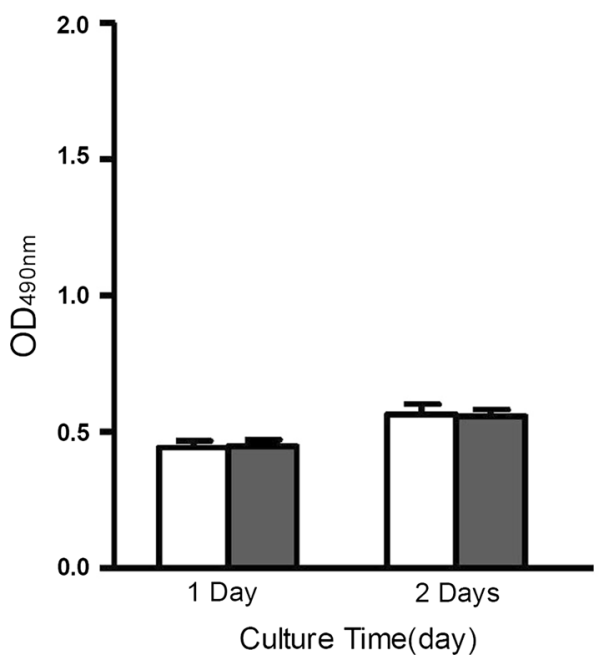

Fig. 6 Cytotoxicity studies of the control and decellularized annulus fibrosus (AF). There were no statistically significant differences between decellularized AF and negative control. Open bar negative control; Closed bar DAF (decellularized AF)

decellularization processes is to minimize disruption, thereby retaining the native mechanical and biological properties of the material. Preliminary studies indicated that decellularization of $\mathrm{AF}$ is complex due to its dense collagenous and GAG-rich nature (Gilbert 2012).

Since rapid freezing of a tissue causes formation of intracellular ice crystals, disruption of cell membranes and cell lysis, we compared $-80{ }^{\circ} \mathrm{C}$ versus liquid nitrogen for physical decellularization. This procedure was followed by chemical treatment to remove cellular material from the tissue. Our data showed that decellularization using liquid nitrogen yielded higher amounts of GAG and collagen compared to freeze-thaw.

Based on their ability to solubilize the cell membrane, ionic detergents such as SDS and non-ionic detergents such as Triton X-100 have been widely studied for tissue decellularization (Crapo et al. 2011; Gilbert et al. 2006). Non-ionic detergents are sometimes more desirable since they have the least impact on protein structure due to their lack of ionic charge, while ionic detergents are considered to be harsher to tissues, with greater disruption of protein structure and loss of matrix components (Gilbert 2012). Early studies reported that SDS was more effective than Triton X-100 for removing nuclei from dense tissues and organs while preserving tissue mechanics (Lumpkins et al. 2008; Nakayama et al. 2010; Pridgen et al. 2011). However, the effectiveness of decellularization using these agents remains unclear due to the variations between different studies in concentrations, temperatures, and times of detergent use. Our present data showed higher retention of collagen and GAG with $0.1 \%$ SDS compared to Triton X-100. Decellularization for $72 \mathrm{~h}$ in $0.1 \%$ SDS effectively removed DNA. However, since there was a higher loss of GAG and collagen compared to the $24 \mathrm{~h}$ decellularization protocol, the optimal decellularization time was determined to be $24 \mathrm{~h}$. Our final optimized decellularization method therefore included the use of liquid nitrogen, an ionic detergent (0.1\% SDS), and a $24 \mathrm{~h}$ incubation period, which yielded the greatest retention of GAG and collagen relative to DNA reduction.

We evaluated the effects of decellularization on the biochemical and biomechanical properties of the resulting scaffold, and whether our decellularization process enabled the retention of collagen and GAG content close to that of the native AF. Our data showed abundant collagen fibrils in both native and decellularized AF, without gross evidence of damage and distribution. There was also no significant difference 

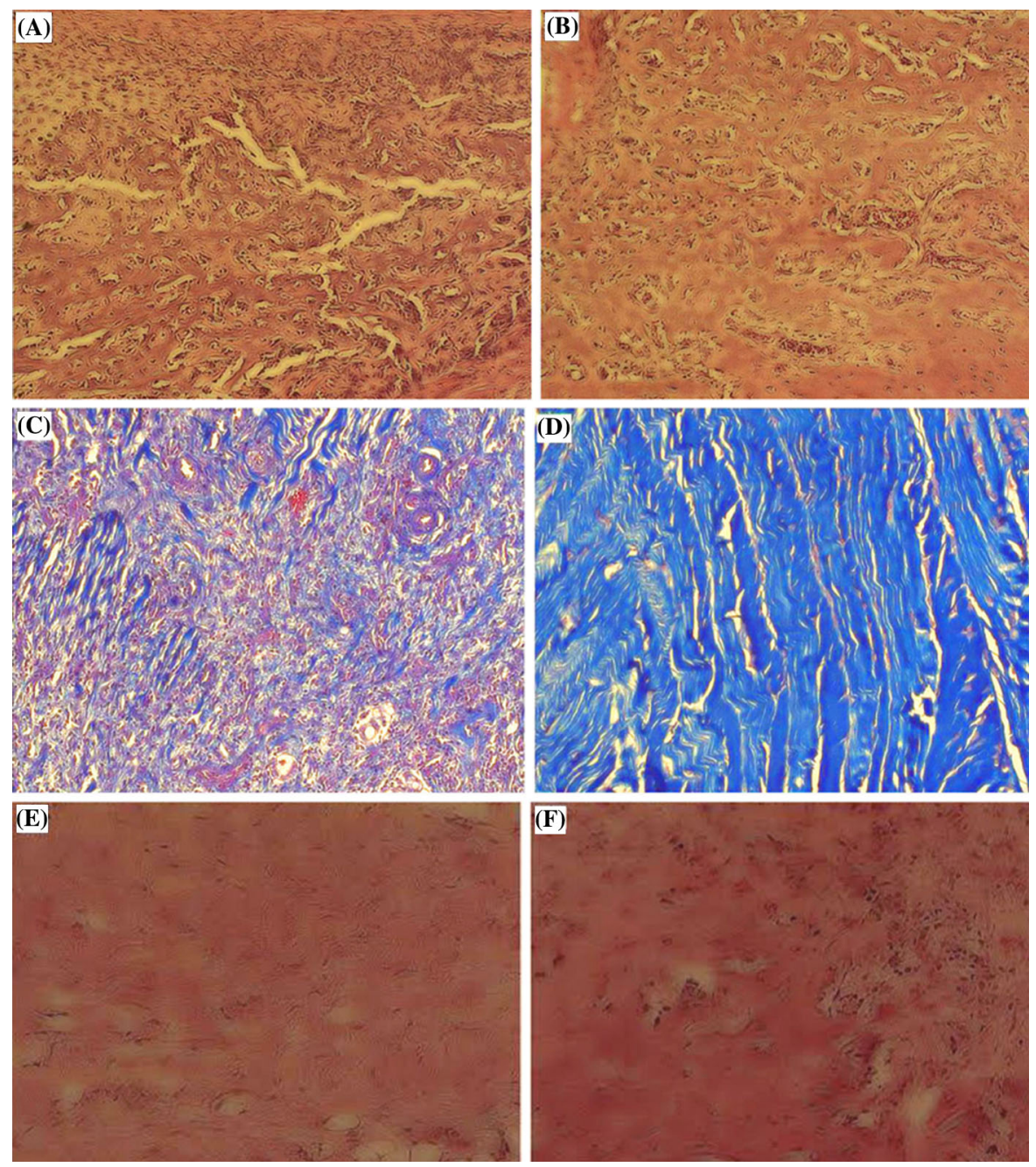

Fig. 7 In vivo immuno-compatibility studies at 7 days. a Control group with H\&E stain, $\times 40$ magnification. b Repair group with $H \& E$ stain, $\times 40$ magnification. $\mathbf{c}$ Control group with MT staining, $\times 40$ magnification. d Repair group with MT staining,

in collagen content between native and decellularized AF. Our present data showed that $5.6 \%$ of GAG was lost during processing, which was an improvement over our previous protocol, which resulted in a $15.9 \%$ loss of GAG (Wu et al. 2014).

Tissues were extensively washed in PBS at the end of the protocol since the chemicals and enzymes used for decellularization can be toxic to host cells upon in vivo implantation if they remain within the tissue after treatment. Simple in vitro cytotoxicity tests to examine the biocompatibility of decellularized AF scaffolds indicated that any residual cytotoxic reagents were successfully removed by the $\times 40$ magnification. e Control group with PAS staining, $\times 40$ magnification. f Repair group with PAS staining, $\times 40$ magnification

washing procedure. In addition, our immune-compatibility data showed that the annulus defects in both control and repair groups in the in vivo study were covered by scar tissue and populated mostly by mononuclear cells on day 7, although the densities of collagen and GAG were higher in the repair group than in controls. Increased organization of collagen distribution in the repair group compared to the control group suggested efficient tissue remodeling in the repair group. Mononuclear cells decreased with time in all samples, while fibroblast-like cell infiltration of the matrix was a key feature of the tissue remodeling observed. 

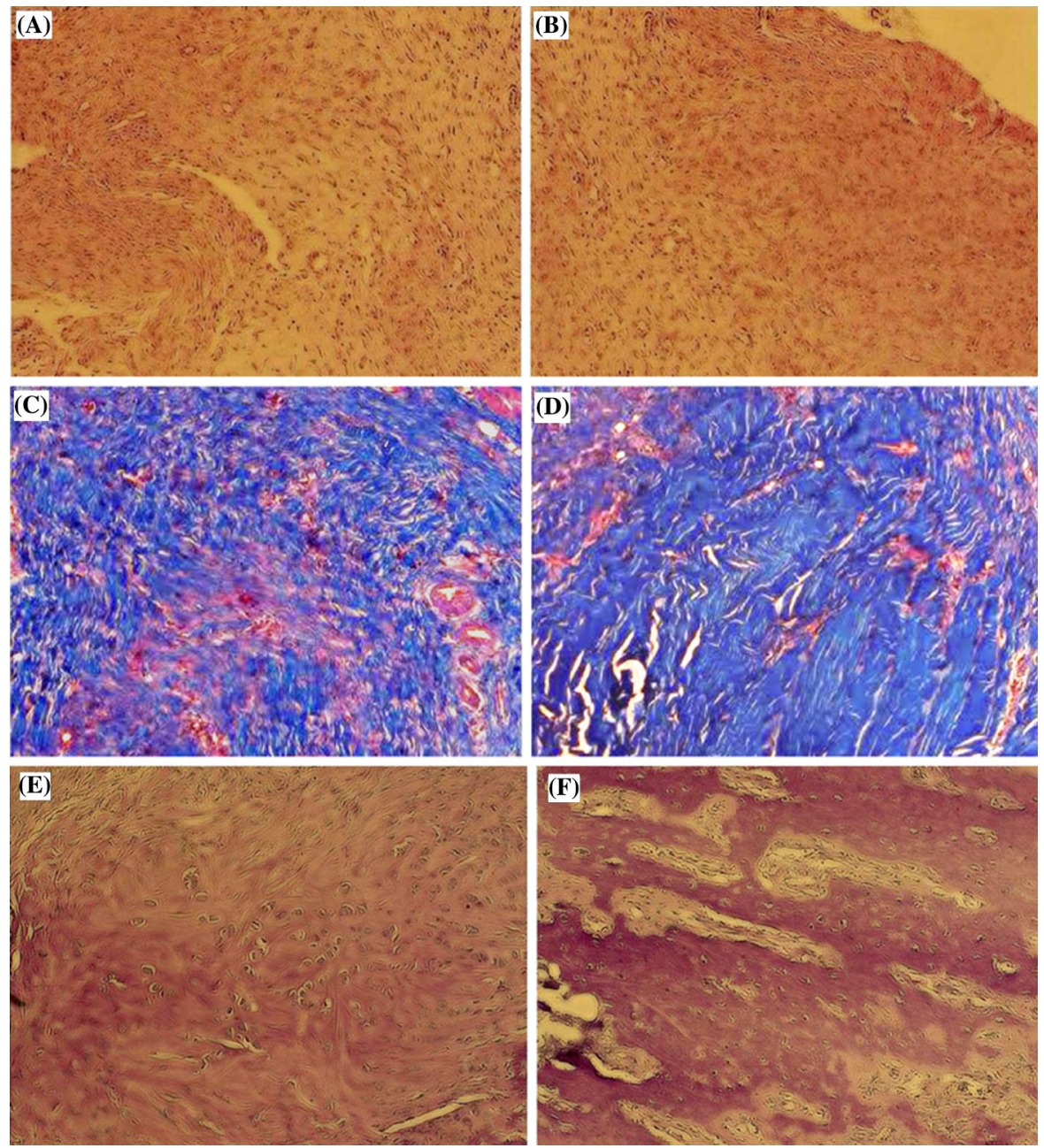

Fig. 8 In vivo immuno-compatibility studies at 14 days. a Control group with $H \& E$ stain, $\times 40$ magnification. b Repair group with $\mathrm{H} \& \mathrm{E}$ stain, $\times 40$ magnification. $\mathbf{c}$ Control group with MT staining, $\times 40$ magnification. d Repair group with MT

staining, $\times 40$ magnification. e Control group with PAS staining, $\times 40$ magnification. $f$ Repair group with PAS staining, $\times 40$ magnification

Devising a successful strategy for AF repair requires a clear understanding of the functional biomechanics of the intervertebral disc. Intervertebral discs serve to support large spinal loads involving combinations of tension, torsion, compression, and bending. Therefore, AF repair materials must withstand the high stresses generated by spinal motion (Jin et al. 2013). Biomechanical testing of the decellularized AF demonstrated no significant difference in Young's modulus, further indicating satisfactory preservation of the biomechanical properties of the native tissue.

Pig-to-human xeno-transplantation offers a potential solution to the shortage of organs for

transplantation. However, xeno-transplantation from pigs to humans induces hyper-acute rejection because the $\alpha$-Gal epitope, expressed in both pigs and humans, is the major antigen inducing complement-mediated cell lysis via human antibodies. Efforts to eliminate the $\alpha$-Gal epitope from xenografts include (1) the production of alpha1,3-galactosyltransferase knockout pigs (Milland et al. 2005; Puga Yung et al. 2012), (2) treatment of xenogeneic tissue with $\alpha$-galactosidase (Goncalves et al. 2005; Choi et al. 2012), and (3) introduction of human complement regulatory protein genes into pig cells. Although the cloning of knockout pigs lacking $\alpha$-Gal epitopes has eliminated the antiGal immune barrier to xeno-transplantation, this 


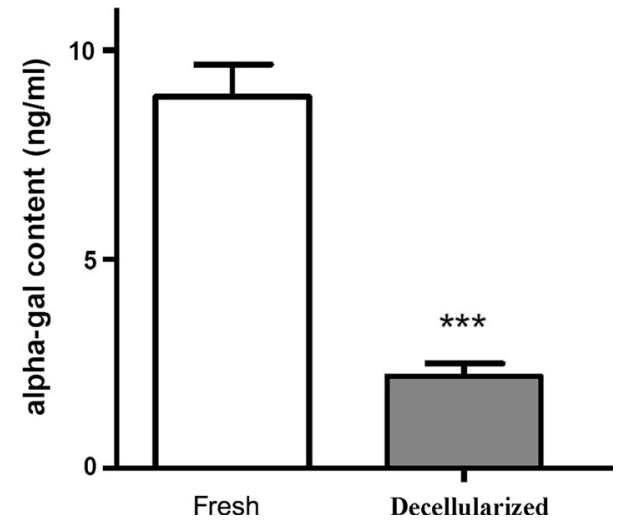

Fig. 9 Quantification of $\alpha$-Gal content. Treatment of annulus fibrosus tissues with the decellularization method resulted in the apparent removal of the $\alpha$-Gal xeno-antigen $(p<0.001)$

process is costly. Modification of $\alpha$-Gal on the cell surface has also been attempted using decellularization. Of the various detergents tested, only SDS is reported to remove these xeno-antigens (Goncalves et al. 2005). Our data suggested that the use of SDS during the decellularization process removed $\alpha$-Gal xeno-antigens. To the best of our knowledge, our study is the first to report quantification of the $\alpha$-Gal epitope in decellularized porcine AF tissues.

Residual $\alpha$-Gal epitopes have been found in commercial bioprostheses of porcine heart valves, SIS-ECM (small intestinal submucosa-extracellular matrix) (Naso et al. 2013; Zheng et al. 2005). Non- $\alpha$-Gal epitopes can also be immunogenic (Lam et al. 2004; Chen et al. 2005). Previous studies investigating the role of the $\alpha$-Gal epitope in the host immune response to SIS-ECM reported that the immuno-modulatory effect of the $\alpha$-Gal epitope did not adversely affect the in vivo remodeling of xenogeneic ECM (Raeder et al. 2002; Daly et al. 2009). Long-term production of anti-non-Gal antibodies against porcine xeno-antigens in human recipients were reported to contribute to a low-level inflammatory process in dense xenografts (Stone et al. 2007).

Most commercially available biologic scaffold materials contain trace amounts of remnant DNA, which is typically present as small fragments and subject to degradation via enzymatic breakdown (Gilbert et al. 2009; Zheng et al. 2005). Although the remaining DNA fragments and $\alpha$-Gal epitopes are known to stimulate an immune reaction, it is possible that a threshold amount of material is required to adversely affect the remodeling response (Badylak and Gilbert 2008). It is unlikely that any combination of methods will remove $100 \%$ of all cell xeno-antigens from a tissue or organ. However, methods that remove most or all of the visible cellular material likely result in biologic scaffold materials that are safe for implantation (Gilbert et al. 2006). Our future work will aim to optimize cell seeding and test the decellularized AF scaffold in a functional largeanimal model of disc repair. These studies will determine the in vivo regenerative capacity of porcine AF scaffolds over the long term.

\section{Conclusions}

A porcine decellularization method including freezethaw in liquid nitrogen, an ionic detergent $(0.1 \%$ $\mathrm{SDS}$ ), and a $24 \mathrm{~h}$ incubation period resulted in an AF scaffold which retained the necessary components of the AF matrix, the ultrastructure of the ECM, and the biomechanical properties of the AF. This decellularization protocol also greatly reduced the immunogenicity of porcine AF. The scaffold was therefore biocompatible and is a potential candidate for clinical use.

Acknowledgements The authors thank Ming-Ju Chou for the technical help.

\section{Compliance with ethical standards}

Competing interests The authors declare that they have no competing interests.

Author contributions F-WS conducted this study and, with L-CW, collected important background information and performed the statistical analysis. Y-HT conceived the study. L-CW participated in the study design and drafted the manuscript. Y-JK, C-JC, C-HC, and Y-YH supervised the research. $\mathrm{Y}-\mathrm{YH}$ revised the manuscript. All of the authors read and approved the final manuscript.

Open Access This article is distributed under the terms of the Creative Commons Attribution 4.0 International License (http:// creativecommons.org/licenses/by/4.0/), which permits unrestricted use, distribution, and reproduction in any medium, provided you give appropriate credit to the original author(s) and the source, provide a link to the Creative Commons license, and indicate if changes were made. 


\section{References}

Badylak SF, Gilbert TW (2008) Immune response to biologic scaffold materials. Semin Immunol 20:109-116

Booth C, Korossis SA, Wilcox HE, Watterson KG, Kearney JN, Fisher J, Ingham E (2002) Tissue engineering of cardiac valve prostheses I: development and histological characterization of an acellular porcine scaffold. J Heart Valve Dis 11:457-462

Bron JL, Helder MN, Meisel HJ, Van Royen BJ, Smit TH (2009) Repair, regenerative and supportive therapies of the annulus fibrosus: achievements and challenges. Eur Spine J 18:301-313

Chan SC, Gantenbein-Ritter B (2012) Intervertebral disc regeneration or repair with biomaterials and stem cell therapy-feasible or fiction? Swiss Med Wkly 142:w13598

Chen G, Qian H, Starzl T, Sun H, Garcia B, Wang X, Wise Y, Liu Y, Xiang Y, Copeman L, Liu W, Jevnikar A, Wall W, Cooper DK, Murase N, Dai Y, Wang W, Xiong Y, White DJ, Zhong R (2005) Acute rejection is associated with antibodies to non-Gal antigens in baboons using Galknockout pig kidneys. Nat Med 11:1295-1298

Choi SY, Jeong HJ, Lim HG, Park SS, Kim SH, Kim YJ (2012) Elimination of alpha-gal xenoreactive epitope: alphagalactosidase treatment of porcine heart valves. J Heart Valve Dis 21:387-397

Crapo PM, Gilbert TW, Badylak SF (2011) An overview of tissue and whole organ decellularization processes. Biomaterials 32:3233-3243

Dahl SL, Koh J, Prabhakar V, Niklason LE (2003) Decellularized native and engineered arterial scaffolds for transplantation. Cell Transpl 12:659-666

Daly KA, Stewart-Akers AM, Hara H, Ezzelarab M, Long C, Cordero K, Johnson SA, Ayares D, Cooper DK, Badylak SF (2009) Effect of the alphaGal epitope on the response to small intestinal submucosa extracellular matrix in a nonhuman primate model. Tissue Eng Part A 15:3877-3888

Farndale RW, Buttle DJ, Barrett AJ (1986) Improved quantitation and discrimination of sulphated glycosaminoglycans by use of dimethylmethylene blue. Biochem Biophys Acta 883:173-177

Gilbert TW (2012) Strategies for tissue and organ decellularization. J Cell Biochem 113:2217-2222

Gilbert TW, Sellaro TL, Badylak SF (2006) Decellularization of tissues and organs. Biomaterials 27:3675-3683

Gilbert TW, Freund JM, Badylak SF (2009) Quantification of DNA in biologic scaffold materials. J Surg Res 152:135-139

Goncalves AC, Griffiths LG, Anthony RV, Orton EC (2005) Decellularization of bovine pericardium for tissue-engineering by targeted removal of xenoantigens. J Heart Valve Dis 14:212-217

Guterl CC, See EY, Blanquer SB, Pandit A, Ferguson SJ, Benneker LM, Grijpma DW, Sakai D, Eglin D, Alini M, Iatridis JC, Grad S (2013) Challenges and strategies in the repair of ruptured annulus fibrosus. Eur Cells Mater 25:1-21

Hongo M, Gay RE, Hsu JT, Zhao KD, Ilharreborde B, Berglund LJ, An KN (2008) Effect of multiple freeze-thaw cycles on intervertebral dynamic motion characteristics in the porcine lumbar spine. J Biomech 41:916-920
Huang H, Zhang J, Sun K, Zhang X, Tian S (2011) Effects of repetitive multiple freeze-thaw cycles on the biomechanical properties of human flexor digitorum superficialis and flexor pollicis longus tendons. Clin Biomech 26:419-423

Jin L, Shimmer AL, Li X (2013) The challenge and advancement of annulus fibrosus tissue engineering. Eur Spine $\mathrm{J}$ 22:1090-1100

Lam TT, Paniagua R, Shivaram G, Schuurman HJ, Borie DC, Morris RE (2004) Anti-non-Gal porcine endothelial cell antibodies in acute humoral xenograft rejection of hDAFtransgenic porcine hearts in cynomolgus monkeys. Xenotransplantation 11:531-535

Lumpkins SB, Pierre N, McFetridge PS (2008) A mechanical evaluation of three decellularization methods in the design of a xenogeneic scaffold for tissue engineering the temporomandibular joint disc. Acta Biomater 4:808-816

Mercuri JJ, Gill SS, Simionescu DT (2011) Novel tissue-derived biomimetic scaffold for regenerating the human nucleus pulposus. J Biomed Mater Res, Part A 96:422-435

Milland J, Christiansen D, Sandrin MS (2005) Alpha 1,3galactosyltransferase knockout pigs are available for xenotransplantation: are glycosyltransferases still relevant? Immunol Cell Biol 83:687-693

Mwale F, Masuda K, Pichika R, Epure LM, Yoshikawa T, Hemmad A, Roughley PJ, Antoniou J (2011) The efficacy of Link $\mathrm{N}$ as a mediator of repair in a rabbit model of intervertebral disc degeneration. Arthritis Res Ther 13:R120

Nakayama KH, Batchelder CA, Lee CI, Tarantal AF (2010) Decellularized rhesus monkey kidney as a three-dimensional scaffold for renal tissue engineering. Tissue Eng Part A 16:2207-2216

Naso F, Gandaglia A, Iop L, Spina M, Gerosa G (2011) First quantitative assay of alpha-Gal in soft tissues: presence and distribution of the epitope before and after cell removal from xenogeneic heart valves. Acta Biomater 7:1728-1734

Naso F, Gandaglia A, Bottio T, Tarzia V, Nottle MB, d'Apice AJ, Cowan PJ, Cozzi E, Galli C, Lagutina I, Lazzari G, Iop L, Spina M, Gerosa G (2013) First quantification of alphaGal epitope in current glutaraldehyde-fixed heart valve bioprostheses. Xenotransplantation 20:252-261

Pridgen BC, Woon CY, Kim M, Thorfinn J, Lindsey D, Pham H, Chang J (2011) Flexor tendon tissue engineering: acellularization of human flexor tendons with preservation of biomechanical properties and biocompatibility. Tissue Eng Part C Methods 17:819-828

Puga Yung GL, Li Y, Borsig L, Millard AL, Karpova MB, Zhou D, Seebach JD (2012) Complete absence of the alphaGal xenoantigen and isoglobotrihexosylceramide in alpha1,3galactosyltransferase knock-out pigs. Xenotransplantation 19:196-206

Rabelo-Goncalves E, Roesler B, Guardia AC, Milan A, Hara N, Escanhoela C, Almeida J, Boin I, Zeitune JM (2014) Evaluation of five DNA extraction methods for detection of H. pylori in formalin-fixed paraffin-embedded (FFPE) liver tissue from patients with hepatocellular carcinoma. Pathol Res Pract 210:142-146

Raeder RH, Badylak SF, Sheehan C, Kallakury B, Metzger DW (2002) Natural anti-galactose alpha1,3 galactose antibodies delay, but do not prevent the acceptance of extracellular matrix xenografts. Transpl Immunol 10:15-24 
Rieder E, Kasimir MT, Silberhumer G, Seebacher G, Wolner E, Simon P, Weigel G (2004) Decellularization protocols of porcine heart valves differ importantly in efficiency of cell removal and susceptibility of the matrix to recellularization with human vascular cells. J Thorac Cardiovasc Surg 127:399-405

Schek RM, Michalek AJ, Iatridis JC (2011) Genipin-crosslinked fibrin hydrogels as a potential adhesive to augment intervertebral disc annulus repair. Eur Cells Mater 21:373-383

Stapleton TW, Ingram J, Katta J, Knight R, Korossis S, Fisher J, Ingham E (2008) Development and characterization of an acellular porcine medial meniscus for use in tissue engineering. Tissue Eng Part A 14:505-518

Stone KR, Abdel-Motal UM, Walgenbach AW, Turek TJ, Galili U (2007) Replacement of human anterior cruciate ligaments with pig ligaments: a model for anti-non-gal antibody response in long-term xenotransplantation. Transplantation 83:211-219

Woods T, Gratzer PF (2005) Effectiveness of three extraction techniques in the development of a decellularized boneanterior cruciate ligament-bone graft. Biomaterials 26:7339-7349
Wu LC, Chiang CJ, Liu ZH, Tsuang YH, Sun JS, Huang YY (2014) Fabrication and properties of acellular porcine annulus fibrosus for tissue engineering in spine surgery. J Orthop Surg Res 9:118

Xu H, Xu B, Yang Q, Li X, Ma X, Xia Q, Zhang Y, Zhang C, Wu Y, Zhang Y (2014) Comparison of decellularization protocols for preparing a decellularized porcine annulus fibrosus scaffold. PLoS ONE 9:e86723

Yang L, Kandel RA, Chang G, Santerre JP (2009) Polar surface chemistry of nanofibrous polyurethane scaffold affects annulus fibrosus cell attachment and early matrix accumulation. J Biomed Mater Res, Part A 91:1089-1099

Zhang L, Dong Y, Dong Y, Cheng J, Du J (2012) Role of integrin-beta3 protein in macrophage polarization and regeneration of injured muscle. $\mathrm{J}$ Biol Chem 287:6177-6186

Zheng MH, Chen J, Kirilak Y, Willers C, Xu J, Wood D (2005) Porcine small intestine submucosa (SIS) is not an acellular collagenous matrix and contains porcine DNA: possible implications in human implantation. J Biomed Mater Res B Appl Biomater 73:61-67 